\title{
IfIIISGUC.ORG
}

"İȘ, GÜç" ENDÜSTRi iLIȘKiLERi VE inSAN KAYNAKLARI DERGiSi

"IS, GUC" INDUSTRIAL RELATIONS AND HUMAN RESOURCES JOURNAL

\section{Yaşam Tatmini Ve Sosyal Dışlanma}

\author{
Life Satisfaction And Social Exclusion
}

\author{
Nuran BAYRAM \\ Doç. Dr. Uludağ Üniversitesi \\ Serpil AYTAÇ \\ Prof. Dr. Uludağ Üniversitesi
}

\section{Neslihan SAM}

Dr. Uludağ Üniversitesi

Mustafa AYTAÇ

Prof. Dr. Uludağ Üniversitesi

Ekim/October 2010, Cilt/Vol: 12, Sayı/Num: 4, Page: 79-92

ISSN: 1303-2860, DOI: 10.4026/1303-2860.2010.0159.x

Makalenin on-line kopyasına erişmek için:

http://www.isguc.org/?p=article\&id=441\&vol=12\&num=4\&year=2010

To reach the on-line copy of article:

http://www.isguc.org/?p=article \&id $=441 \&$ vol $=12 \&$ num $=4 \&$ year $=2010$

Makale İçin İletişim/Correspondence to:

nuranb@uludag.edu.tr, neslihan@uludag.edu.tr 
(C) 2000- 2010

"İşGüç" Endüstri İlişkileri ve İnsan Kaynakları Dergisi

"İşGüç" Industrial Relations and Human Resources Journal

Ekim/October 2010, Cilt/Vol: 12, Say1/Num: 4

ISSN: 1303-2860, DOI: 10.4026/1303-2860.2010.159.x

Editör/Editor-in-Chief

Aşkın Keser (Kocaeli University)

Editör Yardımcıları/Co-Editors

K.Ahmet Sevimli (Uludağ University)

Gözde Yılmaz (Kocaeli University)

Uygulama/Design

Yusuf Budak (Kocaeli Universtiy)

\author{
Yayın Kurulu / Publishing Committee \\ Dr.Zerrin Firat (Uludăg University) \\ Doç.Dr.Aşkın Keser (Kocaeli University) \\ Prof.Dr.Ahmet Selamoğlu (Kocaeli University) \\ Yrd.Doç.Dr.Ahmet Sevimli (Uludağ University) \\ Yrd.Doç.Dr.Abdulkadir Şenkal (Kocaeli University) \\ Yrd.Doç.Dr.Gözde Yilmaz (Kocaeli University) \\ Dr.Memet Zencirkıran (Uludağ University)
}

Uluslararası Danışma Kurulu / International Advisory Board

Prof.Dr.Ronald Burke (York University-Kanada)

Assoc.Prof.Dr.Glenn Dawes (James Cook University-Avustralya)

Prof.Dr.Jan Dul (Erasmus University-Hollanda)

Prof.Dr.Alev Efendioğlu (University of San Francisco-ABD)

Prof.Dr.Adrian Furnham (University College London-İngiltere)

Prof.Dr.Alan Geare (University of Otago- Yeni Zellanda)

Prof.Dr. Ricky Griffin (TAMU-Texas AEM University-ABD)

Assoc. Prof. Dr. Diana Lipinskiene (Kaunos University-Litvanya)

Prof.Dr.George Manning (Northern Kentucky University-ABD)

Prof. Dr. William (L.) Murray (University of San Francisco-ABD)

Prof.Dr.Mustafa Özbilgin (University of East Anglia-UK)

Assoc. Prof. Owen Stanley (James Cook University-Avustralya)

Prof.Dr.Işık Urla Zeytinoğlu (McMaster University-Kanada)

Danışma Kurulu / National Advisory Board

Prof.Dr.Yusuf Alper (Uludağ University)

Prof.Dr.Veysel Bozkurt (Uludağ University)

Prof.Dr.Toker Dereli (Işık University)

Prof.Dr.Nihat Erdoğmuş (Kocaeli University)

Prof.Dr.Ahmet Makal (Ankara University)

Prof.Dr.Ahmet Selamoğlu (Kocaeli University)

Prof.Dr.Nadir Suğur (Anadolu University)

Prof.Dr.Nursel Telman (Maltepe University)

Prof.Dr.Cavide Uyargil (İstanbul University)

Prof.Dr.Engin Yildırım (Sakarya University)

Doç.Dr.Arzu Wasti (Sabancı University)

Dergide yayınlanan yazllardaki görüşler ve bu konudaki sorumluluk yazarlarına aittir.

Yayınlanan eserlerde yer alan tüm içerik kaynak gösterilmeden kullanılamaz.

All the opinions written in articles are under responsibilities of the outhors.

None of the contents published can't be used without being cited. 


\title{
Yaşam Tatmini Ve Sosyal Dışlanma*
}

\author{
Life Satisfaction And Social Exclusion
}

\author{
Nuran BAYRAM \\ Doç. Dr. Uludağ Üniversitesi \\ Serpil AYTAÇ \\ Prof. Dr. Uludağ Üniversitesi
}

\author{
Neslihan SAM \\ Dr. Uludağ Üniversitesi
}

Mustafa AYTAÇ

Prof. Dr. Uludağ Üniversitesi

\begin{abstract}
Özet:
Bu çalışmanın amacı, yaşam tatmini ve sosyal dışlanma boyutları arasındaki ilişkileri incelemek ve yaşam tatminini açıklamada sosyal dışlanma boyutlarının anlamlı bir etkiye sahip olup olmadığını ortaya çıkarmaktır. Çalışmada, yaşam tatminini ölçmek için beş maddeden oluşan yaşam tatmini ölçeği (SWLS) ve sosyal dışlanmayı ölçmek için Jehoel-Gijsbers \& Vrooman (2007) tarafindan geliştirilen ve otuz beş maddeden oluşan sosyal dışlanma ölçeğinden yararlanılmıştır. Çalışmanın örneklemi Bursa ilinde ikamet eden onsekiz yaşüstü 2493 bireyden oluşmaktadır. Çalışmaya katılanların yaklaşık \%55 i erkeklerden oluşmuştur. Yaş ortalaması 38,16 $\pm 12,06$ ve Bursa'da

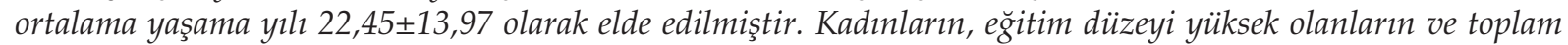
aylık geliri yüksek olanlarn yaşam tatmininin daha yüksek olduğu görülmüş̧ür. Sosyal dişlanma ölçeğinin maddi yoksunluk, sosyal haklar ve sosyal katılımollik boyutlarının yaşam tatminini açıklamada önemli olduğu sonuçlarına ulaşılmıştır.
\end{abstract}

Anahtar Kelimeler: Yaşam Tatmini, Sosyal Dışlanma, Maddi Yoksunluk, Sosyal Haklar, Sosyal Katılımcılık

\begin{abstract}
:
The aim of the study is to examine the relationships between life satisfaction and social exclusion, and is to reveal life satisfaction which dimensions of the social exclusion scale have been explained the best. We used the Satisfaction with Life Scale (SWLS) to measure life satisfaction and the social exclusion scales that were used by JehoelGijsbers $\mathcal{E}$ Vrooman (2007). The sample of the study is consisted of 2493 individuals over the age of eighteen years residing in the city of Bursa. Approximately $55 \%$ of the participants in this study are consisted of males. The average age is $38.16 \pm 12.06$ and the average length of residence in the city is $22.45 \pm 13.97$. It had been found that the females' life satisfaction levels higher than the males. We found that dimensions of social exclusion play a significant role in life satisfaction.
\end{abstract}

Keywords: Life Satisfaction, Social Exclusion, Material Deprivation, Social Rights, Social Participation

\footnotetext{
* Bu çalışmanın genişletilmiş özeti 10. Ekonometri ve İstatistik Sempozyumunda, 27-29 Mayıs 2009 tarihlerinde bildiri olarak sunulmuştur. Çalışma U.Ü. Bilimsel Araştırmalar Projesi Başkanlığında yürü̈tülen İ-2008/73 proje verilerini içermektedir.
} 


\section{Giriş}

Günümüzde küreselleșme sonucu, bir taraftan dünyada artan zenginlikler söz konusu olmasina rağmen, diğer taraftan eşitsizlikler, güvencesizlikler ve adaletsizliklerin giderek yaygınlaşması, beraberinde bireylerin yaşam tatmin düzeylerinin azalmasına ve sosyal dişlanma düzeylerinin yükselmesine yol açmıştır.

Kişinin kendi yaşamına ilişkin genel bir yarg1sı veya değerlendirmesi olarak tanımlanan (Pavot, Diener, Colvin, \& Sandvik, 1991; Shin\&Johnson, 1978) yaşam tatmini kavraminda aile, sosyal yaşam ve yaşama çevresi gibi temel yaşam alanları içinde, genelde yaşamın bilişsel değerlendirmesi ele alınmaktadır (Diener, 1984). Frisch'e göre (2000) yaşam tatmini, kişinin en önemli ihtiyaçları, amaçları ve isteklerinin subjektif değerlendirmesini ifade etmektedir. Bir diğer ifade ile yaşam tatmini, kişinin genel yaşam tatminini, yargılarını veya spesifik yaşam alanını içeren yaşam kalitesinin subjektif değerlendirmesidir (Marques vd., 2007).

Sosyal dışlanma ise, yoksulluk, işsizlik, eşitsizlik, güvencesizlik ve ayrımcılık gibi temel sosyal politika sorunlarını nitelemekle ilgili olup, ekonomik, sosyal ve siyasal tartışmaların gündem maddesi haline gelmiştir (Sapancalı, 2003). Toplumun bir parçası olma ve topluma entegre olmayı yansitan sosyal entegrasyonun tersi olan (Robila, 2006) sosyal dışlanma kavramı yoksunluk kavramı ile yakından ilişkilidir. Sosyal dışlanmanın en önemli unsuru, çok boyutlu dinamik bir yoksunluk süreci oluşudur. Yoksunluk kavramı, genellikle statik bir kavram olarak ele alınırken, sosyal dışlanma önemli dinamik görünümlere sahiptir (Bossert vd., 2007; Sapancalı, 2005, 2009). Eğer bireylerin yoksunluğu devam eder veya zaman içinde daha kötüye giderse, birey sosyal olarak dışlanmış olmaktadır (Chakravarty \& D'Ambrosio, 2006). Townsend (1993) temel gereksinimleri karşılayamama olan maddi yoksunluk düzeyi (yeme-içme, giyinme, barınma vb.) ile sosyal dişlanma (aile, eğlence ve eğitim vb.) arasındaki farkı ortaya koymuştur.
Sosyal dışlanma, hem ekonomik-yapısal hem de sosyo-kültürel biçimde olmak üzere ortaya çıkan çok boyutlu bir olaydır (Bhalla \& Lapeyre, 1997; Chakravarty \& D'Ambrosio, 2006; Jehoel-Gijsbers \& Vrooman, 2007). Commins (1993) sosyal dişlanmayı, vatandaşlık entegrasyonundan dişlanma, işgücü piyasasından dişlanma, sosyal yardım durumundan dişlanma ve aile-toplumdan dişlanma şeklinde dört boyutta ele alırken; Silver (1994) sosyal dışlanma kavramını ekonomik, sosyal, politik ve kültürel boyutlar ile incelemiştir. Jehoel-Gijsbers \& Vrooman $(2007,2008)$ sosyal dişlanmayı maddi yoksunluk, sosyal haklar, sosyal katılımcilık ve kültürel entegrasyon olmak üzere dört farklı boyutta ele almıştır. Sapancalı (2003) sosyal dişlanmayı mal ve hizmet piyasalarından dışlanma ve işgücü piyasasından dışlanmayı içeren ekonomik alandan dişlanma, mülkiyet ve konuttan dişlanma ve sosyal refah hizmetlerinden dişlanmayı içeren toplumsal hayattan dışlanma, demokrasi, haklar ve yönetim ile göçmenler ve azınlıkları içeren siyasal alandan dişlanma şeklinde üç boyutta ele almıştır. Adaman \& Keyder (2005) sosyal dışlanmayı ekonomik dışlanma, mekansal dışlanma, kültürel dışlanma ve politik dıșlanma şeklinde dört boyutta ele almıştır. Pek çok yazar ise, sosyal dişlanma kavramını, yoksullaşma veya yeterli gelir ve kaynaklardan dışlanma, işgücünden dişlanma, hizmetlerden dişlanma ve sosyal ilişkilerden dışlanma şeklinde dört boyutta ele almıştır (Gordon vd. 2000).

Yerli ve yabancı literatüre bakıldı̆̆ında yaşam tatmini ve sosyal dişlanma kavramları ile ilgili çok fazla bilimsel yayına rastlanmakta ve bu kavramların ya ayrı ayrı yada farklı kavramlar ile birlikte ele alındığ 1 görülmektedir. Fakat, bu iki kavramın bir arada ele alındığı çalışma hemen hemen yok denilecek kadar azdır.

Türkçe literatüre bakıldığında çalışmaların bir kısmının, yaşam tatmini kavramının iş tatmini ile ilişkisini (Keser, 2005; Aşan \& Erenler, 2008), kariyer bağlılığı, mesleki bağlılık ve örgütsel bağlılık kavramları ile ilişkisini (Özdevecioğlu \& Aktaş, 2007), mesleki 
ve sosyo-ekonomik beklenti ile ilişkisini (Can \& Soyer, 2008) ve akademik başarı ile ilişkisini (Güler \& Emeç, 2006) inceledikleri görülmektedir.

Bununla birlikte, literatürde az sayıda da olsa yaşam tatmini ile sosyal dişlanma kavramı ile yakından ilişkili olan yoksulluk ve işsizlik arasındaki ilişkilerin incelendiği çalışmalara rastlanmaktadır. Heady, Krause ve Wagner (2009) tarafından yapılan çalışmada yaşam tatminini açıklamada yoksulluğun etkili olduğu elde edilmiştir (Gilbert, 2009). Rojas (2008) tarafından yapılan çalışmada bireyin yaşam tatmini düşük ise deneyimli yoksulluğa sahip olduğu ortaya çıkarılmıştır. Clark vd. (2001) ve Clark (2003) tarafından yapılan çalışmalarda ise yaşam tatmini üzerinde işsizliğin negatif bir etkisi olduğu ortaya konulmuştur.

Yaşam tatmini ile sosyal dişlanma arasında yapılan az sayıda çalışmadan biri olan ve Shields vd. (2009) tarafından yapılan çalışmada yaşam tatmini ile sosyal dişlanma arasında negatif bir ilişki bulunmuştur. Ayrıca yine aynı çalışmada sosyal dışlanmanın, yaşam tatminindeki değişkenliği açıklamada az da olsa bir etkiye sahip olduğu ortaya konulmuştur. Szukielojc-Bienkunska (2005) tarafından yapılan bir çalışmada sosyal dışlanma göstergeleri arasında düşük yaşam tatmini ele alınmıştır. Almanya'da yaşayan göçmenlerin sosyal dişlanma düzeylerini belirlemeye yönelik yapılan çalışmada ise istihdam ve yaşam tatmini ile sosyal dişlanma arasında güçlü bir ilişki bulunmuştur (Haisken-DeNew \& Sinning, 2007).

Türkçe literatür incelendiğinde yoksulluk üzerine çok fazla çalışma yapılmasına karşın sosyal dişlanma kavramı üzerine çok fazla çalışmaya rastlanamamaktadır. Sapancalı $(2003,2005)$ tarafından yapılan çalışmalarda sosyal dişlanma kavramı teorik olarak her yönü ile ele alınmıştır. Adaman \& Keyder (2005) ve Adaman \& Ardıç (2008) tarafından yapılan çalışmada ise sosyal dişlanmanın Türkiye'deki durumu yoksul mahallelere özel vurgu yapılarak hem teorik hem de uygulamalı yönü ile incelenmiştir.
2010 y1lı Avrupa Parlamentosu ve Avrupa Konseyi tarafından Avrupa Yoksulluk ve Sosyal Dışlanma ile Mücadele Yılı olarak ilan edilmiştir. Bu kapsamda, bu çalışmada diğer çalışmalardan farklı olarak sosyal dışlanma ve boyutları ilk kez bir ölçek yardımı ile ele alınmış ve yaşam tatmini ile aralarındaki ilişkiler ortaya konulmaya çalışılmıştır. Çalışmada sosyal dışlanma kavramı JehoelGijsbers \& Vrooman (2007) tarafından geliştirilen ölçek kullanılarak maddi yoksunluk, sosyal haklar, sosyal katılımcılık ve kültürel entegrasyon olmak üzere dört boyutta incelenmiştir. Çalışmanın amacı yaşam tatmini ve sosyal dışlanma boyutları arasındaki ilişkileri incelemek ve yaşam tatminini açıklamada sosyal dışlanma boyutlarının anlamlı bir etkiye sahip olup olmadığını ortaya koymaktır.

\section{Yöntem}

\section{Veri Toplama Araçları}

Çalışmada kullanılan anket formunda katılımcılara ait çeşitli sosyo-demografik değişkenlerin yanı sıra yaşam tatmini ölçeği ve sosyal dışlanma ölçeği yer almıştır.

Yaşam Tatmini Ölçeği: Çalışmada, yaşam tatminini ölçmek için, 7'li likert tipinde beş maddeden oluşan yaşam tatmini ölçeği (SWLS) kullanılmıştır (Diener. et al., 1985; Pavot and Diener, 1993). Ölçekte yer alan her bir madde "kesinlikle katılmıorum" ile "kesinlikle katılıyorum" arasında değişmektedir. Ölçekten elde edilen yüksek değerler yüksek yaşam tatminini göstermektedir.

Sosyal Dışlanma Ölçeği: Çalışmada sosyal dışlanmayı ölçmek için Jehoel-Gijsbers \& Vrooman (2007) tarafından geliştirilen ve tarafımızdan revize edilerek Türkçe literatüre geçerlilik ve güvenilirlik analizi yapılarak kazandırılmış olan 5'li likert tipinde otuz beş maddeden oluşan sosyal dişlanma ölçeği kullanılmıştır. Bu ölçekte maddi yoksunluk, sosyal haklara ulaşma, sosyal katılımcılık ve kültürel entegrasyon olmak üzere dört boyut mevcuttur. Ölçekte sosyal haklara ulaşma boyutu iki ayrı alt boyut şeklinde ele alınmaktadır. Birinci alt boyut sosyal haklar 
bağlaminda kurumlardan ve yardımlardan faydalanabilmeyi kapsarken, ikinci alt boyut ise uygun ev ve güvenli çevreden faydalanabilmeyi kapsamaktadır. Ölçekte yer alan her bir madde "hiç bir zaman" ile "her zaman" arasında değişmektedir. Sosyal dışlanma ölçeğinde yer alan boyutlar ve tanımları Tablo 1'de sunulmuştur.

Sosyal dişlanma ölçeğinde her bir boyut için elde edilen yüksek değerler, sosyal dışlanma düzeyinin yüksek olduğunu göstermektedir. Diğer bir ifade ile, yüksek değerler maddi yoksunluğun yüksek olduğunu, kurumlardan ve yardımlardan yararlanılamadığını, uygun ev ve güvenli çevre koşullarına sahip olunmadığını, sosyal katılımcılığın düşük olduğunu (sosyal katılımcılığ 1 başaramama) ve kültürel entegrasyon ve normlara uymanın başarılamadığını göstermektedir.

\section{Katılimcilar}

Çalışmanın örneklemi Bursa ilinde ikamet eden onsekiz-seksen yaş arası bireylerden oluşmaktadır. 2493 bireyin katıldığ 1 çalışmada veriler Tabakalı Örnekleme yöntemine göre toplanmış ve tabakalarda yeralan örneklem hacimleri orantılı dağıtım yöntemi ile belirlenmiştir. Türkiye İstatistik Kurumu, Adrese Dayalı Nüfus Kayıt Sistemi (ADNKS) Veri Tabanına (2008) göre Bursa kent merkez ilçeleri dahilinde nüfus 1,813,452'dir. Bu anakütle için tölere edilebilir örneklem hatası \%3 olarak alındığında \%99 güven düzeyi için örneklem hacmi 1847 olarak belirlenmiştir. Çalışma grubu olarak

\section{Tablo 1}

Sosyal dışlanma ölçeğinin boyutları ve tanımları

\begin{tabular}{|c|c|}
\hline Sosyal Dişlanma Ölçeği & Tanımı \\
\hline I. Boyut: Maddi yoksunluk & $\begin{array}{l}\text { Zorunlu ödemelerin güçlükle yapılması, maddi durum hakkında } \\
\text { endişelenme, beslenme, giyim, barınma gibi temel gereksinmelerin } \\
\text { yeterince karşılanamaması. }\end{array}$ \\
\hline II. BoyutA: Sosyal haklar & $\begin{array}{l}\text { Hastane, vergi dairesi, nüfus müdürlüğü gibi kamu kurumlarında } \\
\text { sorun yaşama ve kötü muamele ile karşılaşma, kredi ve sigorta mü- } \\
\text { racaatlarının reddedilmesi, bireylerin yararına olacak uygulama- } \\
\text { larda haklarının verilmemesi. Diğer bir ifade ile, kamu } \\
\text { kurumlarından ve yardımlarından faydalanılamaması. }\end{array}$ \\
\hline II. BoyutB: Sosyal haklar & $\begin{array}{l}\text { Yaşanılan çevrenin gürültülü ve kirli olması, çevrede sürekli olay- } \\
\text { lar çıkması, komşuluk ilişkilerinin iyi olmaması, kişinin kendisini } \\
\text { güvende hissetmemesi ve evde tek başına olmaktan korkması. } \\
\text { Diğer bir ifade ile, uygun ev ve güvenli çevre koşullarına sahip } \\
\text { olunmaması. }\end{array}$ \\
\hline III. Boyut: Sosyal katılımcılık & $\begin{array}{l}\text { Kişinin kendisini toplumdan dişlanmış hissetmesi, sosyal ilişki ku- } \\
\text { rabileceği kişi sayısının çok az olması, sırlarını paylaşabileceği ar- } \\
\text { kadaşlarının olmaması ya da çok az olması, kişinin } \\
\text { arkadaşlarından çok az sosyal destek görmesi ve diğer insanlarla } \\
\text { olan ilişkilerinde sorun yaşaması. }\end{array}$ \\
\hline $\begin{array}{l}\text { IV. Boyut: Kültürel entegrasyon, } \\
\text { normlara uyma }\end{array}$ & $\begin{array}{l}\text { Kişinin arkadaşlarının yararına olacaksa yalancı şahitlik yapması, } \\
\text { yakalanmadığı sürece kanunları çiğnemesi, ücretli olarak çalışan- } \\
\text { ların ek bir işte daha çalışmalarını uygun bulması, işsizlik parası } \\
\text { veya sosyal yardım parası alanların ek iş yapmalarını uygun bul- } \\
\text { ması ve başkalarının emekli veya sigorta karnelerini kullanarak üc- } \\
\text { retsiz muayene olunmasını veya ilaç alınmasını uygun karşılaması. }\end{array}$ \\
\hline
\end{tabular}


belirlenen örneklem hacminin üzerine çıkılması hedeflenmiş ve orantılı dağıtım yaklaşımı ile 3000 adet anket merkez ilçelere dağıtılmıştır. Geriye dönen anket sayısı 2753 olmuş ancak eksik gözlemlerin varlığından ve tutarsiz anket doldurulmasindan hareketle 260 gözlem çalışma dışı bırakılarak toplam 2493 veri üzerinden analizler yürütülmüştür.

Çalışmada verilerin analiz edilmesinde SPSS 16.0 paket programindan yararlanılmış ve frekans dağılımları, güvenilirlik analizi, ttesti, korelasyon analizi ve hiyerarşik regresyon analizi kullanılmıştır.

\section{Bulgular}

Çalışmaya katılanların yaşları 18-80 arasinda değişmekte olup, ortalama yaş $38,16 \pm 12,06$ (ortalama \pm s.sapma) ve Bursa'da yaşama yılı 1-72 yıl arasında değişmekte olup, ortalama yaşama yılı ise $22,45 \pm 13,97$ olarak elde edilmiştir. Çalışmaya katılanların yaklaşık \%55 i erkeklerden oluşmuştur. Çalışma grubunun yaş ve cinsiyet dağılımı Tablo 3'de gösterilmiştir.

Çalışmaya katılanların \%68,1'inin lise mezunu olduğu, \%14,6'sının herhangi bir sosyal güvenceye sahip olmadığ1, \%15,9'unun

\section{Tablo 2}

Bursa merkez ilçelerine göre anakütle ve örneklem hacminin yüzde dağılımı

\begin{tabular}{|l|c|c|}
\hline & \multicolumn{2}{|c|}{ \% Dağılım } \\
\hline Bursa Kenti Merkez İlçeleri & Anakütle & Örneklem \\
\hline Osmangazi & 40.80 & 38.4 \\
\hline Yildirim & 32.68 & 30.1 \\
\hline Nilufer & 14.18 & 18.1 \\
\hline Mudanya & 2.60 & 2.7 \\
\hline Gemlik & 4.99 & 5.5 \\
\hline Gursu & 2.77 & 2.9 \\
\hline Kestel & 1.98 & 2.4 \\
\hline Toplam & $\mathbf{1 0 0 . 0}$ & $\mathbf{1 0 0 . 0}$ \\
\hline
\end{tabular}

Tablo 3

Çalışma grubunun yaş ve cinsiyet dağılımı

\begin{tabular}{lcccccc}
\hline \multirow{2}{*}{ Yaş grupları } & \multicolumn{2}{c}{ Kadın } & \multicolumn{2}{c}{ Erkek } & \multicolumn{2}{c}{ Toplam } \\
\cline { 2 - 7 } & $\mathrm{N}$ & $\%$ & $\mathrm{~N}$ & $\%$ & $\mathrm{~N}$ & $\%$ \\
\hline $18-28$ & 342 & 30,5 & 315 & 23,0 & 657 & 26,4 \\
$29-39$ & 306 & 27,2 & 407 & 29,7 & 713 & 28,6 \\
$40-50$ & 327 & 29,1 & 412 & 30,1 & 739 & 29,6 \\
$51+$ & 148 & 13,2 & 236 & 17,2 & 384 & 15,4 \\
\hline Toplam & 1123 & 100,0 & 1370 & 100,0 & 2493 & 100,0 \\
\hline
\end{tabular}


Tablo 4

Cronbach $\alpha$ değerleri

\begin{tabular}{lccccc}
\hline Ölçekler & Madde & Ortalama & S.Sapma & C. Alpha & C. Alpha \\
\hline $\begin{array}{l}\text { Sosyal Dışlanma } \\
\quad \text { Boyut I: Maddi Yoksunluk }\end{array}$ & 8 & 20,81 & 6,31 & 0,79 & 0,89 \\
$\quad \begin{array}{l}\text { Boyut IIA: Sosyal Haklar } \\
\text { (kurum ve yardımlardan } \\
\text { faydalanma) }\end{array}$ & 5 & 11,43 & 4,52 & 0,82 & 0,82 \\
$\quad$ Boyut IIB: Sosyal Haklar & & & & & \\
$\begin{array}{l}\text { (uygun ev ve güvenli çevreden } \\
\text { faydalanma) }\end{array}$ & 8 & 15,20 & 5,66 & 0,80 & 0,71 \\
$\quad \begin{array}{l}\text { Boyut III: Sosyal Katılımcllık } \\
\quad \text { Boyut IV: Kültürel }\end{array}$ & 9 & 18,90 & 5,43 & 0,77 & 0,76 \\
$\begin{array}{l}\text { Entegrasyon } \\
\text { Yaşam Tatmini }\end{array}$ & 5 & 11,12 & 3,66 & 0,67 & 0,61 \\
\hline
\end{tabular}

Jehoel-Gijsbers \& Vrooman (2007) sonuçları

Tablo 5

Cinsiyete göre $t$-testi sonuçları

\begin{tabular}{lcccc}
\hline Ölçekler & Kadın $(\mathrm{n}=1123)$ & Erkek $(\mathrm{n}=1370)$ & $t$ & $\mathrm{p}$ \\
\hline Sosyal Dışlanma & & & & \\
$\quad$ Boyut I: Maddi Yoksunluk & $20,74 \pm 6,49$ & $20,92 \pm 6,61$ &, 685 &, 493 \\
$\quad$ Boyut IIA: Sosyal Haklar & $11,17 \pm 4,58$ & $11,73 \pm 4,82$ & 2,950 &, 003 \\
$\quad$ Boyut IIB: Sosyal Haklar & $16,54 \pm 6,29$ & $15,90 \pm 5,96$ & $-2,597$ &, 009 \\
$\quad$ Boyut III: Sosyal Katılımcılık & $18,46 \pm 5,49$ & $19,11 \pm 5,56$ & 2,915 &, 004 \\
$\quad$ Boyut IV: Kültürel & $11,16 \pm 3,75$ & $11,26 \pm 3,99$ &, 662 &, 508 \\
Entegrasyon & $20,74 \pm 6,50$ & $19,99 \pm 7,04$ & $-2,735$ &, 006 \\
Yaşam Tatmini & & & &
\end{tabular}

ekonomik durumunun kötü olduğu, $\% 22$ 'sinin ailedeki toplam fert sayısının 5 ve üstü olduğu ve \%35'inin de oturduğu evin kira olduğu tespit edilmiştir. Çalışmada kullanılan ölçeklere ait güvenilirlik analizi sonuçları ortalamalar ve standart sapmalarla birlikte Tablo 4'de sunulmuştur.

Cinsiyete göre yapılan analiz sonucunda sosyal dişlanma ölçeğinin maddi yoksunluk boyutunda ve kültürel entegrasyon boyutunda istatistiksel olarak anlamlı bir farkl1lık bulunamamıştır. Bununla birlikte sosyal dişlanma ölçeğinin sosyal haklar ve sosyal katılımcılık boyutlarında ve yaşam tatmini ölçeğinde cinsiyete göre istatistiksel olarak $\% 1$ anlamlılık düzeyinde anlamlı bir farklılık bulunmuştur. 


\section{Tablo 6}

\section{Ölçeklerarası korelasyonlar}

\begin{tabular}{lccccc}
\hline & Yaşam Tat. & Boyut I & BoyutIIA & BoyutIIB & BoyutI \\
\hline Boyut I: Maddi Yoksunluk &,$- 314^{* *}$ & & & & \\
Boyut IIA: Sosyal Haklar &,$- 250^{* *}$ &, $453^{* *}$ & & & \\
Boyut IIB: Sosyal Haklar &,$- 232^{* *}$ &, $245^{* *}$ &, $322^{* *}$ & & \\
Boyut III: Sosyal Katılımcllık &,$- 257^{* *}$ &, $288^{* *}$ &, $266^{* *}$ &, $270^{* *}$ & \\
Boyut IV: Kültürel Entegrasyon &,- 070 &, $156^{* *}$ &, $132^{* *}$ &, $179^{* *}$ &, $163^{* *}$ \\
\hline
\end{tabular}
${ }^{*} \mathrm{p}<0.01$

Öçekler arası korelasyonlar incelendiğinde, sosyal dışlanma ölçeğinin dördüncü boyutu olan kültürel entegrasyon ve normlara uyma ile yaşam tatmini arasında istatistiksel olarak anlamlı bir ilişki bulunamamıştır. Diğer tüm boyutlar ile yaşam tatmini arasında istatistiksel olarak \%1 anlamlılık düzeyinde ters yönlü ilişkiler elde edilmiştir. Yaşam tatmini ile maddi yoksunluk boyutu arasında en yüksek ilişki $(\mathrm{r}=-0,31, \mathrm{p}<0,01)$ elde edilmiştir. Bu durumda, kişilerin maddi yoksunluk düzeyleri arttıkça, sosyal haklara ulaşamama düzeyleri arttıkça ve sosyal katılımcılığı başaramadıkça yaşam tatmini düzeylerinin azaldığını söylemek mümkündür.
Sosyal dıșlanma ölçeğinin tüm alt boyutları arasında aynı yönlü \%1 anlamlılık düzeyinde istatistiksel olarak anlamlı ilişkiler elde edilmiştir. Bunlar arasında en yüksek ilişki, maddi yoksunluk ile kurumlardan ve yardımlardan faydalanamama $(\mathrm{r}=0,45$, $p<0,01)$ arasında elde edilmiştir.

Değişkenler arası korelasyonlar incelendiğinde, yaşam tatmini ile cinsiyet, eğitim durumu ve gelir değişkenleri arasında istatistiksel olarak anlamlı ilişkiler bulunmuştur. Sosyal dışlanma ölçeğinin boyutları arasinda ise, maddi yoksunluk boyutu ile eğitim durumu, sosyal güvence, gelir ve kira durumu değişkenleri arasında; kurum ve yardımlardan yararlanma boyutu ile gelir ve

\section{Tablo 7}

Değişkenlerarası Korelasyonlar

\begin{tabular}{lcccccc}
\hline & Yaşam Tat. & Boyut I & BoyutIIA & BoyutIIB & BoyutIII & BoyutIV \\
\hline Yaş &, 045 &,- 066 &,- 069 &,$- 139^{* *}$ &, 054 &,$- 094^{*}$ \\
Cinsiyet $^{1}$ &, $103^{*}$ &, 039 &,- 040 &,- 016 &,$- 142^{* *}$ &, 002 \\
Egitim Durumu $^{2}$ &, $128^{* *}$ &,$- 237^{* *}$ &,- 065 &,- 008 &,$- 095^{*}$ &,- 053 \\
Sosyal Güvence $^{3}$ &,- 031 &,$- 123^{* *}$ &,- 040 &,- 030 &, 000 &,- 056 \\
Toplam Aylık &, $225^{* *}$ &,$- 304^{* *}$ &,$- 097^{*}$ &,- 003 &,$- 144^{* *}$ &,- 016 \\
Gelir &, 071 &,$- 163^{* *}$ &,$- 085^{*}$ &,$- 095^{*}$ &,- 019 &,$- 110^{* *}$ \\
Kira Durumu $^{*}$ &, 07 N $^{* *}$ &
\end{tabular}

${ }^{*} \mathrm{p}<0.05$; ${ }^{\text {** }} \mathrm{p}<0.01$; ${ }^{1}$ Cinsiyet: 1-Erkek, 2-Kadın; ${ }^{2}$ Eğitim durumu: 1-En fazla lise, 2-Üniversite ve üstü;

${ }^{3}$ Sosyal Güvence: 1-Var, 2-Yok; ${ }^{4}$ Kira durumu: 1-Kira 2-Kira değil 
kira durumu değişkenleri arasında; uygun ev ve güvenli çevre koşulu boyutu ile yaş ve kira durumu değişkenleri arasında; sosyal katılımcılık boyutu ile cinsiyet, eğitim durumu ve gelir değişkenleri arasında; kültürel entegrasyon boyutu ile yaş ve kira durumu değişkenleri arasında istatistiksel olarak anlamlı ilişkiler bulunmuştur.

Çalışmanın bu aşamasında yaşam tatminini sosyal dışlanma ölçeğinin hangi boyutlarının daha iyi açıkladığını ortaya çıkarmak amacıyla regresyon analizi yapılmıştır. Analiz sonuçları aşağıdaki tabloda yeralmaktadir.

Kurulan model ile yaşam tatminini açıklamada birinci adımda yeralan kimlik ve sosyo-ekonomik durum değişkenleri içerisinde toplam aylık gelir ve cinsiyet değişkeninin önemli olduğu ve ele alınan değişkenler ile toplam değişkenliğin \%8'nin açıklandığı görülmüştür. İkinci adımda ilave edilen sosyal dişlanma boyutları ile toplam değişkenliğin \%19'u açılanmış ve yine kimlik ve sosyo-ekonomik durum değişkenleri içerisinde toplam aylık gelir ve cinsiyet değişkenleri yaşam tatminini açılamada önemli bulunmuştur. Bununla birlikte, sosyal dışlanma boyutlarında ise, sırası ile maddi yoksunluk, sosyal haklar ve sosyal katılımcılık boyutlarının yaşam tatminini açıklamada önemli bir etkiye sahip olduğu ortaya konulmuştur.

Tablo 8

Yaşam tatmini bağımlı değişkeni için hiyerarşik regresyon analizi

\begin{tabular}{lcc}
\hline Değişkenler & 1. Adım & 2. Adım \\
\hline Yaş &, 058 &, 037 \\
Cinsiyet $^{1}$ &, $098^{*}$ &, $080^{*}$ \\
Eğitim durumu ${ }^{2}$ &, 078 &, 040 \\
Sosyal güvence ${ }^{3}$ &,- 062 &,- 075 \\
Toplam aylık gelir &, $205^{* *}$ &, $145^{* *}$ \\
Ailedeki toplam kişi sayısı &,- 057 &,- 034 \\
Kira durumu &, 071 &, 022 \\
Boyut I: Maddi Yoksunluk & &,$- 162^{* *}$ \\
Boyut IIA: Sosyal Haklar & &,- 085 \\
Boyut IIB: Sosyal Haklar & &,$- 127^{* *}$ \\
Boyut III: Sosyal Katılımcılık & &,$- 119^{* *}$ \\
Boyut IV: Külttürel Entegrasyon & &, 015 \\
\hline R $^{2}$ & & $0,19^{* *}$ \\
\hline
\end{tabular}




\section{Tartışma ve Sonuç}

$\mathrm{Bu}$ çalışmada yaşam tatmini ve sosyal dışlanma kavramları incelenmiş ve istatistiksel analizler ile aralarındaki ilişkiler ortaya konulmaya çalışılmıştır. Korelasyon analizi sonucunda kadınların, eğitim düzeyi yüksek olanların ve toplam aylık geliri yüksek olanların yaşam tatmin düzeylerinin daha yüksek olduğu sonuçları elde edilmiştir. Bununla birlikte, yapılan t-testi sonucunda, yaşam tatmini değeri incelendiğinde kadınların erkeklere nazaran daha yüksek yaşam tatmin düzeyine sahip olduğu tespit edilmiştir. OECD (2005) raporuna bakıld1ğında, OECD ülkeleri arasında Türkiye, Kore ve Japonya'da kadınların erkeklere nazaran daha yüksek yaşam tatmin düzeyine sahip olduğu ve kadın-erkek arasında en fazla farklılığın Türkiye'de olduğu görülmektedir. Fakat bu ülkelerde kadın ve erkek yaşam tatmin düzeylerinin OECD ülkelerinin ortalamasının altında olduğu dikkati çekmektedir. Diğer yandan, OECD ülkelerinin ortalamasının üstünde olan ülkeler arasinda yer alan Avustralya, Belçika ve Finlandiya gibi ülkelerde de kadınların erkeklere nazaran daha yüksek yașam tatmin düzeyine sahip olduğu tespit edilmiştir.

Adaman \& Keyder (2005) ve Adaman \& Ardıç (2008) tarafından yapılan çalışmalarda cinsiyet değişkeninde sosyal dişlanmışlık hissinin farklılık yaratmadığ 1 sonucu elde edilmiştir. Fakat, Bradshaw vd. (2000) yaptığ1 çalışmada kadınların erkeklere nazaran daha fazla sosyal dişlanmışlık hissine sahip olduğu sonucu bulunmuştur. Mevcut çalışmada ise kurum ve sosyal yardımlardan yararlanma ile sosyal katilımcilık alt boyutlarında erkeklerin kadınlara nazaran kendilerini daha fazla sosyal dışlanmış hissettikleri ve uygun ev ve güvenli çevre koşullarına sahip olma boyutunda ise kadınların erkeklere nazaran kendilerini daha fazla sosyal dışlanmış hissettikleri elde edilmiştir.

Sosyal dışlanma ölçeğinin uygun ev ve güvenli çevre koşullarına sahip olma boyutu ile yaş değişkeni arasında ters yönlü bir ilişki bulunmuştur. Buna göre genç yaşta olanla- rın uygun ev ve güvenli çevre koşullarına sahip olma boyutunda sosyal dışlanmışlık hissinin yaşlı nüfusa nazaran daha yüksek olduğu söylenebilir. Gençlerin yaşlı nüfusa nazaran daha fazla sosyal dışlanmışlık hissine sahip olduğu sonucu Jehoel-Gijsbers \& Vrooman (2007), Poggi (2003), Aasland \& Flotten, (2001), Adaman \& Keyder (2005) ve Adaman \& Ardıç (2008) tarafından yapılan çalışmalarda da elde edilmiştir.

Çalışmada eğitim düzeyi arttıkça maddi yoksunluk ve sosyal katılımcilık boyutlarında daha az sosyal dişlanmışlık hissine sahip olunduğu sonucuna uluşılmıştır. Bu sonuç, Aasland \& Flotten (2001), Poggi (2003), Adaman \& Keyder (2005), Adaman \& Ardıç (2008) ve Devicienti \& Poggi (2007) tarafından yapılan çalışmalarda da elde edilmiştir. Bunun yanı sıra, maddi yoksunluk boyutu ile gelir değişkeni ve eğitim düzeyi değişkeni arasında bulunan ters yönlü ilişki Boarini \& d'Ercole (2006) bulguları ile de örtüşmektedir.

Sosyal güvencesi olanların olmayanlara nazaran maddi yoksunluk boyutunda sosyal dışlanmışlık hissinin daha az olduğu, kirada oturanların ise kendi evi olanlara nazaran sosyal dışlanmışlık düzeyinin daha yüksek olduğu ve toplam aylık geliri yüksek olanlarin maddi yoksunluk, kurum ve yardımlardan faydalanma ve sosyal katılımcilık boyutlarında sosyal dışlanmışlık hissinin diğerlerine nazaran daha az olduğu sonuçlarına ulaşılmıştır.

Çalışmada, Shields vd. (2009) ve Szukielojc-Bienkunska (2005) tarafından yapılan çalışmalarda olduğu gibi, yaşam tatmini ile sosyal dışlanma boyutları arasında negatif ilişkiler bulunmuştur. Bu durumda, yaşam tatmini yüksek olan bireylerin sosyal dışlanmişlık düzeylerinin düşük olduğu söylenebilir. Tüm bunlara ek olarak, çalışmada yaşam tatminindeki değiş̧kenliği açıklamada sosyal dişlanmışlığın istatistiksel olarak anlamlı bir etkiye sahip olduğu sonucu ortaya konulmuştur. Bu sonuç, Shields vd. (2009) tarafından yapılan çalışmanın bulguları ile örtüşmektedir. 


\section{KAYNAKLAR}

Adaman Fikret, Keyder Çağlar, (2005), Türkiye'de Büyük Kentlerin Gecekondu Ve Çöküntü Mahallelerinde Yaşanan Yoksulluk Ve Sosyal Dişlanma, Türkiye Raporu: (Erişim tarihi: 25.11.2008)

Adaman, F., Ardic, O.P., (2008), Social exclusion in the slum areas of large cities in Turkey. New Perspectives on Turkey 38 (1), 29-60.

Aşan E., Erenler E., (2008), İş tatmini ve Yaşam Tatmini İlişkisi, Süleyman Demirel Üniversitesi, İktisadi veİdari Bilimler Fakültesi Dergisi, Y.2008, C.13, S.2 s.203-216

Boarini Romina \& d'Ercole Marco Mira, (2006), Measures of Material Deprivation in OECD Countries, OECD Social, Employment and Migration Working Papers, ELSA/ELSA/WD/SEM6

Bossert W., D'Amnrosio C., Peragine V., (2007), Deprivation and Social Exclusion, Economica, 74, 777-803

Bradshaw, J., Williams, J., Levitas, R., Pantazis, C., Patsios, D., Townsend, P., Gordon, D., Middleton, S., (2000), The Relationship Between Poverty and Social Exclusion In Britain. 26th General Conference of the International Association for Research in Income and Wealth, Cracow, Poland. (www.stat.gov.pl)

Can Y., Soyer F., (2008), Mesleki ve SosyoEkonomik Beklenti İle Yaşam Tatmini Arasındaki İlişki: Beden Eğitimi Öğretmenleri Üzerinde Bir Araştırma, Beden Eğitimi Ve Spor Bilimleri Dergisi, Cilt 10 , Say1 4.

Chakravarty S. R., D'Ambrosio C., (2006), The Measurement of Social Exclusion, Review of Income and Wealth, Series 52, Number 3, September
Clark, A. E., (2003), Unemployment as a Social Norm: Psychological Evidence from Panel Data. Journal of Labor Economics 21 (2), 323-51.

Clark, A. E., Y. Georgellis, and P. Sanfrey, (2001), Scarring: The Psychological Impact of Past Unemployment. Economica 68 (270), 221-41.

Commins, P. (Ed.)., (1993), Combating exclusion in Ireland 1990-1994: A midway report. Brussels: Observatory on National Policies to Combat Social Exclusion, Commission of European Countries.

Devicienti F., Poggi A., (2007), Poverty and social exclusion: two sides of the same coin or dynamically interrelated processes?, Working Paper no. 62, Laboratorio R. Revelli, Collegio Carlo Alberto, Via Real Collegio, 30 - 10024 Moncalieri (TO); http:/ /www.laboratoriorevelli. it/_pdf/wp62.pdf

Diener, E., (1984), 'Subjective well being', Psychological Bulletin, 95(3), pp. 542575.

Diener, E., Emmons, R.A., Larsen, R.J., \& Griffin, S., (1985), The satisfaction with life scale. Journal of Personality Assessment, 49, 71-75.

Frisch, M. B., (2000), 'Improving mental and physical health care through quality of life therapy and assessment', in Diener, E. and Rahtz, D. R. (eds), Advances in Quality of Life Theory and Research, Dordrecht, The Netherlands, Kluwer Academic Press

Gilbert N., (2009), "European Measures of Poverty and Social Exclusion: Material Deprivation, Consumption and Satisfaction," Journal of Policy Analysis and Management, 28:4. 
Gordon, D., Adelman, A., Ashworth, K., Bradshaw, J., Levitas, R., Middleton, S., Pantazis, C., Patsios, D., Payne, S., Townsend, P. and Williams, J., (2000), Poverty and social exclusion in Britain. Joseph Rowntree Foundation, York.

Güler B. K., Emeç H., (2006), Yaşam Memnuniyeti ve Akademik Başarıda İyimserlik Etkisi, D.E.Ü.İ.I.B.F. Dergisi, Cilt:21 Say1:2, ss:129-149

Haisken-DeNew John P., Sinning Mathias, (2007), Social Deprivation and Exclusion of Immigrants in Germany, November 2007, IZA Discussion Paper No. 3153

Jehoel-Gijsbers Gerda \& Vrooman Cok, (2007), Explaining Social Exclusion: A theoretical model tested in the Netherlands, , The Netherlands Institute for Social Research/scp, The Hague, July 2007

Jehoel-Gijsbers Gerda \& Vrooman Cok, (2008), Social Exclusion of The Elderly A Comparative Study of EU Member States, Enepri Research Report No. 57, AIM WP8.1,September 2008

Keser A., (2005), İş Doyumu ve Yaşam Doyumu İlişkisi: Otomotiv Sektöründe Bir Uygulama, Çalışma ve Toplum, 2005/4, 77-96.

Marques S. C.\& J. L. Pais-Ribeiro \& Shane J. Lopez, (2007), Validation of a Portuguese Version of the Students' Life Satisfaction Scale, Applied Research in Quality of Life 2:83-94

Neil Gilbert, (2009), European Measures of Poverty and "Social Exclusion": Material Deprivation, Consumption, and Life Satisfaction, Journal of Policy Analysis and Management, Vol. 28, No. $4,738-744$
OECD, (2005), Society at a Glance, OECD, Paris; EFILWIC (2003), Quality of Life in Europe: an illustrative report, European Foundation for the Improvement of Living and Working Conditions, Dublin; World Value Surveys.

Özdevecioğlu M., Aktaş A., (2007), Kariyer Bağlılığı, Mesleki Bağlılık ve Örgütsel Bağlılığın Yaşam Tatmini Üzerindeki Etkisi: İş-Aile Çatışmasının Rolü, Erciyes Üniversitesi İktisadi ve İdari Bilimler Fakültesi Dergisi, Sayı: 28, Ocak-Haziran 2007, ss.1-20

Pavot, W. \& Diener, E., (1993), Review of the Satisfaction with Life Scale. Psychological Assessment, 5(2), 164-172.

Pavot, W., Diener, E., Colvin, \& Sandvik, E., (1991), Further validation of the Satisfaction With Life Scale: Evidence for the cross-method convergence of wellbeing measures. Journal of Personality Assessment, 57(1), 149-161.

Poggi Ambra, (2003), Measuring social exclusion using the capability approach, http:/ / www.uia.mx/humanismocristiano/seminario_capability/pdf/16.pdf

Robila Mihaela, (2006), Economic pressure and social exclusion in Europe, The Social Science Journal 43, 85-97

Rojas Mariano, (2008), Experienced Poverty and Income Poverty in Mexico: A Subjective Well-Being Approach, World Development Vol. 36, No. 6, pp. 10781093.

Sapancalı F., (2003), Sosyal Dışlanma, Dokuz Eylül Üniversitesi İktisadi ve İdari Bilimler Fakültesi yayın No: 09.1600.0000.000/DK

Sapancalı F., (2005), Avrupa Birliği'nde Sosyal Dişlanma Sorunu ve Mücadele Yöntemleri, Çalışma ve Toplum, 2005/3, 51-106. 
Sapancalı, F., (2009), Toplumsal Açıdan Yaşam Kalitesi, Altın Nokta Basım Yayın Dağıtım, İzmir

Shields Michael A., Price Stephen Wheatley, Wooden Mark, (2009), Life satisfaction and the economic and social characteristics of neighbourhoods, J Popul Econ, 22:421-443

Shin, D.,\&Johnson, D., (1978), Avowed happiness as an overall assessment of the qualty of life, Social Indicators Research, 5, 475-492.

Silver, H., (1994), Social exclusion and social solidarity: three paradigms. International Labor Review 133 (5-6), 531-578.

Szukielojc-Bienkunska Anna, (2005), Poverty and social exclusion in Poland, Seminar on poverty measurement, Paris, 30 November - 2 December 2005

Townsend, P., (1993), The International Analysis of Poverty. London: Harvester Wheatsheaf. 